\title{
Targeting and the Impacts of India's MGNREGS
}

Yanyan Liu, Christopher B. Barrett, Nancy H. Chau, Upasak Das, Klaus Deininger, Sara Gustafson, Sudha Narayanan, Megan Sheahan, and Vidhya Soundararajan

\section{Highlights}

- MGNREGS has shown striking heterogeneity in pro-poor targeting across states.

- The declining demand for MGNREGS in recent years is due mainly to local implementation failures that discourage workers.

- In Andhra Pradesh, MGNREGS significantly improved the welfare of participating households, especially the poor, scheduled castes and tribes, and casual laborers.

- It is desirable to provide MGNREGS work during the agricultural lean seasons when work opportunities are scarce - rather than the peak seasons. 
India's Mahatma Gandhi National Rural Employment Guarantee Scheme (MGNREGS), established in 2006, constitutes the world's largest public works project to date. MGNREGS began as part of a 2005 law providing rural households with the legal right to employment for up to 100 days per year at a statelevel agricultural minimum wage. This is the only program in the world to combine a government workforce program with a legal entitlement. Since 2006, the program has generated about 28 billion person days of paid work for a total budget of US $\$ 78$ billion, that is, US $\$ 2.8$ government support per person day of employment generated.

However, the implementation of the MGNREGS has been controversial. On one hand, supporters point to awareness and participation rates, especially among women, which were significantly higher than those in previous or comparable programs. Anecdotal evidence suggests that the MGNREGS has contributed to decentralization, transparency of political processes, and female empowerment. On the other hand, critics note the program's high cost, inefficiency in transferring resources, and - in some contexts - severe corruption. They point out that high program wages may lead to leakage and corruption that may undermine program impacts and cause potential adverse spillover effects on private employers, child laborers, and other unintended consequences.

Empirical analysis of the implementation and impact of MGNREGS can help us better understand whether these arguments are justified. Evidence-based policy advice is especially crucial given that currently the MGNREGS seems to be at the crossroads - fund allocations have plateaued and the wages under the MGNREGA have remained unchanged in real terms and lagged far behind rural wages and are below minimum wages. Word is that the MGNREGA will be given a quiet burial.

This brief discusses the main questions investigated in the evaluation on targeting, implementation and impact of the MGNREGS. They include whether MGNREGS has been effectively targeting the poor population at the national and the state level, whether women have been effectively included in the MGNREGS program, whether the program's flawed implementation has discouraged people to seek MGNREGS work, whether government-supported job creation has crowded out private employment and other types of work, weather the program's targeting has been attenuated by political reasons, and whether the program has resulted in appreciable welfare and poverty impacts.

\section{Data}

In this evaluation, the nationally representative National Sample Survey data from 2009-2010 and 2011-2012 was used to provide a comprehensive overview of MGNREGS implementation and targeting. A three-round household survey dataset in Andhra Pradesh, a state which has seen relatively successful MGNREGS implementation, was used to examine the program's impacts on welfare and household labor supply and to provide empirical evidence regarding the extent to which project spending follows patterns of politically influenced non-programmatic distribution. The other data used includes MGNREGS administrative data, Indian Population Census 2001, Indian Agricultural Census 2005/2006, Indian Village Amenities Census 2001, and Election outcome data from various sources.

\section{Project Findings}

MGNREGS has largely been a successful social safety net in terms of poverty reduction. However, there are several areas that need improvement. 


\section{Heterogeneous Pro-Poor Targeting in the National Rural Employment Guarantee}

Scheme (Liu and Barrett, Economic and Political Weekly 2013)

Using 2009-10 National Sample Survey data, this study described patterns of job-seeking, rationing, and participation in the MGNREGS. At the national level, the self-targeting design of MGNREGS led to greater rates of self-selection into the program by poorer and scheduled tribe or scheduled caste households. However, the administrative rationing of MGNREGS jobs was not pro-poor but demonstrates a rather middle-class bias. At the state level, roughly half of 27 states exhibited rationing and participation profiles that signal effective pro-poor targeting; the other half struggled to avoid high rates and regressive patterns of administrative rationing of jobs to which the poor have a legal right.

\section{Women participation and rationing in the employment quarantee scheme (Narayanan and Das, Economic and Political Weekly 2014)}

This evaluation examined the extent to which MGNREGS includes women. The main focus was on vulnerable sub-populations of women, such as widows and mothers of young children, as these women typically face serious constraints to labor market participation. The study investigated whether or not women have equal access to direct wage employment benefits and at how MGNREGS design and implementation determines participation of women. The results showed that women's participation in the program is much higher than women's participation in similar casual labor work in the private labor market. In addition, women's wages under MGNREGS are comparable to those of men, while in the private labor market, women's wages are typically only half of men's wages. However, while the MGNREGS program has indeed been inclusive of women in these ways, substantial variations across states and across sub-populations remain. In some areas, more traditional social values and norms - such as objections to women working outside the home or perceptions of certain types of work as inappropriate for women - appear to continue to restrict women's access to employment, even with the MGNREGS program's nominal prioritization of women's inclusion.

The 'discouraged worker effect' in public works programs: Evidence from the MGNREGA in India (Narayanan et al., World Development 2017)

Both total MGNREGS expenditure and person days of MGNREGS employment have declined since reaching a peak in 2009. Such a decline could occur either because people no longer need employment assistance or because few people seek employment as they have little confidence in the program even though they desire work. This study provides evidence supporting the latter explanation, namely a "discouraged worker effect". Administrative failures in MGNREGS implementation - failure to provide jobs to which applicants have a legal right, or delays in paying workers for jobs completed - make workers less likely to seek employment. The changes in demand for MGNREGS employment are negatively and significantly associated with the uncertainty of obtaining MGNREGS work in the district, as represented by rationing rates at the district level. Payments delays are likewise associated with reduced subsequent demand for MGNREGS work when household liquidity is stressed due to rainfall shocks.

Policymakers and others may have misinterpreted the decline in demand for MGNREGS as a sign of reduced need for employment guarantees. The study's findings, however, provide a more nuanced and 
accurate interpretation. The observed decline in demand for and participation in MGNREGS employment appears largely a result of local implementation failures that discourage workers from applying to the program, despite the continuing need for the employment guarantee as a safety net.

\section{Heterogeneous Welfare impacts of India's National Rural Employment Guarantee} Scheme: Evidence from Andhra Pradesh (Deininger and Liu, World Development 2019)

This study provides evidence that participants in districts exposed to the program for only one year significantly increased their protein and energy intake. In districts with longer exposure, the major impact was that MGNREGS beneficiaries were able to accumulate more non-financial assets. Such benefits were most pronounced for the poor, scheduled castes and tribes, and households supplying casual labor. This could suggest that the self-targeting mechanism built into MGNREGS is functioning effectively. While every rural household has the legal right to MGNREGS work, richer households tend to have less incentive to apply for this work than poorer households. The results also suggested that increased income from casual labor formed the primary channel through which both the short and medium-term welfare effects were realized.

\section{General equilibrium impacts of National Rural Employment Guarantee Scheme on wel- fare and poverty reduction (Liu 2018)}

This study focused on the general equilibrium (or spillover) effects of MGNREGS on welfare, poverty, and women's empowerment. The results suggest that MGNREGS has positive effects on consumption expenditure and nutritional intake for both participating and non-participating households in program areas. As in the previous study, the welfare effects were more pronounced for poor households. The results also suggest that the program significantly increased female empowerment in districts with two years of implementation.

\section{Disaggregated labor supply implications of guaranteed employment in India (Sheahan et al. 2016)}

This study explored how the MGNREGS program affects how different groups of individuals spend their time. These labor effects were disaggregated by gender, age group, task, and season. Participation in the MGNREGS program appeared to increase the overall household labor supply by about 13 days, but only during the summer slack labor season, mostly attributed to adult women. However, the results suggested that MGNREGS work did crowd out some labor previously dedicated to private casual labor opportunities; this was especially true during the two main agricultural seasons. Despite overall labor displacement, women increased their time spent on farm during the rabi (winter) agricultural season. Time spent on paid and unpaid activities, including household chores, did not increase for youth and children in MGNREGS-participating households; this suggests that there was no within-household substitution of labor toward younger members.

Preferential resource spending under an employment quarantee: The political economy of MGNREGS in Andhra Pradesh (Sheahan et al., World Bank Economic Review 2018)

This study investigated whether MGNREGS spending at the mandal (sub-district) level is susceptible to political influence in Andhra Pradesh. Utilizing administrative data on MGNREGS expenditures from 
2006-2007 to 2012-2013 fiscal years, this study found no evidence of partisan-based spending before the 2009 election. A mandal's political leanings played only a small part in the distribution of funds following the 2009 election. It appears that most variation in MGNREGS expenditures is due to the observed needs of potential beneficiaries, as the scheme intended. Thus, the distortionary effect of politically driven resource allocation is very small.

\section{Political activism as a determinant of strategic transfers: Evidence from an Indian public works program (Chau, Liu and Soundararajan 2019)}

This study looked at the role of political influence on MGNREGS participation at the household level rather than the mandal level in Andhra Pradesh. Specifically, this study examined if there is any evidence of targeting MGNREGS benefits at the household level by village leaders. This study provides robust evidence of targeting in support of rival party affiliates. Furthermore, politicians target voters who are active in political campaigns and also tend to be well-connected. Activists receive more benefits in villages where citizen involvement in the political process is less common, in remote or less-connected villages where they could play a dominant role as information providers, and in villages with a higher share of households belonging to the same or lower caste as the activists' in which case they may act as powerful influencers in the caste-based network. This suggests that strategic transfers are made to voters to not only directly influence them, but also to activists to influence them and their political messages to others.

\section{Recap of Main Findings}

1. At the national level, MGNREGS does seem to target the rural poor effectively. However, there is striking heterogeneity across states, not just in rates of rationing and participation but also in the progressivity or regressive nature of the rationing and participation profiles.

2. MGNREGS has generally included women successfully. However, substantial variations remain both across states and across sub-groups of women.

3. The declining demand for MGNREGS in recent years has been mainly due to local implementation failures that discourage workers, rather than to the program itself becoming irrelevant.

4. In Andhra Pradesh, MGNREGS significantly improves the welfare of participating households, especially the poor, scheduled castes and tribes, and casual laborers.

5. In Andhra Pradesh, MGNREGS has significant positive spillover effects. Specifically, non-participating households also benefit from higher consumption expenditure and nutritional intake. These spillover effects are more pronounced for the poor.

6. In Andhra Pradesh, MGNREGS participation increases the total household labor supply, with some "crowding out" effects on private employers during the two main agricultural seasons. The employment stimulus effects are larger for females than males and concentrated mainly in the slack, summer season.

7. In Andhra Pradesh, MGNREGS fund allocation at the mandal level is based largely on the needs of potential beneficiaries as intended, suggesting that a top down approach to implementation (more target driven, less demand driven) as is the case with Andhra Pradesh, is successful in limiting political influence in allocations to the mandals. However, we did find evidence supporting local (gram panchayat) politicians' use of transfers to leverage the influence of activists over the decision-making of other electors at the household level. 


\section{Policy Recommendations}

Overall, the findings from this project support MGNREGS' achievement as an effective social safety net program. However, it is noteworthy that many of the findings are based on data from Andhra Pradesh, a state where people applauded their accountability and transparency. Moreover, the results have highlighted several actions to improve MGNREGS implementation, as well as the design and implementation of public works programs in other contexts. Specifically, future program implementation should focus on reducing unmet demand among poor and vulnerable populations and ensuring timely payment for work performed.

For a social safety net program such as MGNREGS to be successful, it must have the potential to be scaled up during times of economic stress in order to help populations in need. In order to ensure proper implementation capacity, policymakers must gain a clearer understanding of how the program is working at the local levels, including how and where administrative rationing of jobs occurs and whether such rationing discourages potential workers from applying for the program. Monitoring and evaluation of local MGNREGS performance is critical to understand changing demand for program employment.

Improving the implementation of the MGNREGS program will also require proper targeting, in terms of both program beneficiaries and program timing. For example, the findings showed that societal norms in some states may be acting to reduce women's participation in MGNREGS labor. Program implementation should include strategies to identify under-served and vulnerable populations and ensure equitable representation. The findings of large interstate differences in targeting effectiveness highlight the potential to improve performance by extracting lessons from states with exemplary pro-poor targeting performance and applying those findings to states where targeting towards the poor could improve. The findings on the heterogeneity in local politicians' strategic targeting to political activists shed light on the locations more vulnerable to politically influenced nonprogrammatic distribution.

The timing of MGNREGS labor can also play an important role in the program's overall success. For example, to minimize the "crowding out" of labor previously spent on non-MGNREGS tasks, such as private casual labor, it will be desirable to provide MGNREGS works during the agricultural lean seasons - when work opportunities are scarce - rather than the peak seasons. Most of the expanded labor supply associated with MGNREGS appears to occur in the lean season, among adult women.

Finally, from a research perspective, most current studies of MGNREGS have focused on assessing program impacts after one or two years' implementation. It will be useful to evaluate the longer-term impacts of the program on poverty and development.

\section{ABOUT THE AUTHORS}

Yanyan Liu is a senior research fellow and Sara Gustafson is a communications specialist at the International Food Policy Research Institute.

Christopher B. Barrett and Nancy H. Chau are professors in the Dyson School of Applied Economics and Management at Cornell University.

Upasak Das is an Academic residential fellow at the Global Development Institute, University of Manchester.

Klaus Deininger is the lead economist at the Development Research Group of the World Bank. 
Sudha Narayanan is an associate professor at the Indira Gandhi Institute of Development Research, Mumbai, India.

Megan Sheahan is an associate at Industrial Economics, Incorporated.

Vidhya Soundararajan is an assistant professor in Economics at Indian Institute of Management Bangalore (IIMB).

\section{ACKNOWLEDGMENTS}

We acknowledge the funding support from IFPRI-led CGIAR research program on Policies, Institutions and Markets (PIM) and 3ie.

\section{REFERENCES}

Chau, Nancy H., Yanyan Liu, Vidhya Soundararajan (2018). "Political Activism as a Determinant of Strategic Transfers: Evidence from an Indian Public Works Program," with Nancy Chau and Vidhya Soundararajan, IZA DP No. 11277.

Deininger, Klaus and Yanyan Liu (2019). "Heterogeneous Welfare Impacts of India's National Rural Employment Guarantee Scheme: Evidence from Andhra Pradesh", World Development, 117: 98-111.

Liu, Yanyan. (2018). "General equilibrium impacts of National Rural Employment Guarantee Scheme on welfare and poverty reduction", unpublish manuscript, International Food Policy Research Institute, Washington, DC.

Liu, Yanyan and Christopher B. Barrett (2013). "Heterogeneous Pro-Poor Targeting in India: Mahatma Gandhi National Rural Employment Guarantee Scheme", Economic and Political Weekly, 48(10): 46-53.

Narayanan, Sudha and Upasak Das (2014). Women Participation and Rationing in the Employment Guarantee Scheme. Economic \& Political Weekly, 49(46): 46-53.

Narayanan, Sudha, Upasak Das, Yanyan Liu, and Christopher B. Barrett (2017). "The 'discouraged worker effect' in public works programs: Evidence from the MGNREGA in India", World Development, 100: 31-44.

Sheahan, Megan, Yanyan Liu, Christopher B. Barrett, and Sudha Narayanan (2018). "Preferential resource spending under an employment guarantee: The political economy of MGNREGS in Andhra Pradesh", World Bank Economic Review, 32(3): 551-569.

Sheahan, Megan, Yanyan Liu, Christopher B. Barrett, and Sudha Narayanan (2016). "Disaggregated labor supply implications of guaranteed employment in India", Selected Paper at Agricultural and Applied Economics Association (AAEA) Annual Meeting, July 31-August 2, 2016 Boston, Massachusetts.

Funding for this work was provided by IFPRI-led CGIAR research program on Policies, Institutions and Markets (PIM). This publication has been prepared as an output of 3ie: Impact Evaluation of India's NREG and has not been independently peer reviewed. Any opinions expressed here belong to the author(s) and are not necessarily representative of or endorsed by IFPRI. 